\title{
Low temperature enhanced ductility of friction stir processed 5083 aluminum alloy
}

\author{
EHAB A EL-DANAF*, MAGDY M EL-RAYES and MAHMOUD S SOLIMAN \\ Mechanical Engineering Department, Centre of Excellence for Research in Engineering Materials (CEREM), \\ College of Engineering, King Saud University, P.O. Box 800, Riyadh 11421
}

MS received 10 April 2010

\begin{abstract}
Commercial 5083 Al rolled plates were subjected to friction stir processing (FSP) with two different processing parameters, having 430 and $850 \mathrm{rpm}$ tool rotational speed with a single traverse feed rate of $90 \mathrm{~mm} / \mathrm{min}$. These FSP conditions resulted in two fine grained microstructures of $0.95 \mu \mathrm{m}(430 \mathrm{rpm})$ and $2.6 \mu \mathrm{m}(850 \mathrm{rpm})$. Tensile elongations were measured at a relatively low temperature of $250^{\circ} \mathrm{C}$ at three strain rates, and demonstrated that a decrease in grain size resulted in significantly enhanced ductility and lower forming loads. The occurrence of a relatively high value of strain rate sensitivity, $m$ of 0.45 for a grain size of $0.95 \mu \mathrm{m}$, suggests the operation of superplastic deformation under these present experimental conditions.
\end{abstract}

Keywords. AA5083; friction stir processing; ductility; superplasticity.

\section{Introduction}

Friction stir processing (FSP) is a new solid state processing technique which is essentially a local thermomechanical metal working process that changes the local properties without influencing properties of the bulk material. FSP was developed (Mishra and Mahoney 2004) mainly for microstructural modification in metallic materials, based on the basic principles of friction stir welding (FSW). In FSP, a rotating tool containing a shoulder and a pin provides frictional heating and mechanical mixing in the area covered by the tool in a moving monolithic plate. In addition, the large processing strain results in microstructural refinement and homogenization. Another area in which FSP shows a lot of promise is in the creation of superplastic materials (Ma et al 2002; Cavalierea et al 2005; Johannes et al 2007). FSP creates a region called the 'stir zone' or 'nugget', where the microstructural refinement occurs with equiaxed ultrafine grains with high angle grain boundaries. The resultant microstructure in the nugget region can present the ideal conditions for superplasticity in some materials.

AA5083 is a non-heat treatable aluminum alloy that has excellent corrosion resistance and weldability combined with good strength and formability. It is the material of choice for superplastic automotive and aerospace aluminum panels. There are many grain refinement methods, based on severe plastic deformation (Azushima et al 2008), currently being investigated for producing superplastic materials. These include equal channel angular

\footnotetext{
*Author for correspondence (edanaf@ksu.edu.sa)
}

pressing (ECAP) (Park et al 2003), accumulative roll bonding (ARB) (Eizadjou et al 2009) and various other thermo-mechanical processing techniques (Hsiao and Huang 2002). A continuously cast AA5083 sheet was friction stir processed and cold rolled in order to compare the properties with the as-cast and rolled material (Johannes et al 2007). It was found that the inclusion of FSP step, before rolling and recrystallization, refined the recrystallized grain size, increased the tensile elongations by a factor of $2-3$ at a temperature of $510^{\circ} \mathrm{C}$, giving the material greater forming capabilities.

The deformation behaviour of superplastic materials have been divided into three deformation regions (Soliman 1994; Mohammed 2002), designated as I, II and III at low, intermediate and high strain rates, respectively. In region $\mathrm{II}$, the material is characterized by high strain rate sensitivity index, $m \sim 0.5$, and the activation energy is very close to that of grain boundary diffusion, and maximum ductility is usually observed. In regions III and I, $m$ decreases to a lower value of $\leq 0 \cdot 2$, and ductility is less. Region I has not been observed by many investigators (Soliman 1995; Yousefiani and Mohammed 1998; Duong and Mohamed 2000) when using superpure superplastic materials and region III was attributed to the operation of dislocation creep (Abo-Elhkier and Soliman 2006). It has been established recently that region I does not represent a genuine change in the rate controlling mechanism, but rather arises from operation of a threshold process due to segregation of impurity atoms on the grain boundaries (Chaudhury and Mohamed 1988; Mohamed 1988).

The objective of the present paper is to evaluate FSP technique and its capability of achieving microstructures 
with very fine grain sizes and high grain boundary misorientations, and the possibility of these microstructures in achieving enhanced ductility at relatively lower forming temperatures.

\section{Experimental}

Cold rolled sheets of AA5083, $3 \mathrm{~mm}$ thickness, was used in the present investigation. The tool used had a diameter of $4 \mathrm{~mm}$ with a height of $2.7 \mathrm{~mm}$. The shoulder diameter was $15 \mathrm{~mm}$. The tool material was H13 tool steel, heat treated to about $50 \mathrm{HRc}$. The friction stir progression direction was normal to the rolling direction in the supplied rolled plates. Miniature tensile specimens were machined, normal to the FSP progression direction, such that the gauge length was $2.5 \mathrm{~mm}$ and exactly located in the nugget zone. Two rotation speeds of 430 and $850 \mathrm{rpm}$ with a single traverse speed of $90 \mathrm{~mm} / \mathrm{min}$ were used. The tensile samples were wire cut, and then mechanically ground and polished to a final thickness of about $2 \mathrm{~mm}$. Tensile tests were conducted at $250^{\circ} \mathrm{C}$ at three strain rates and the true stress-strain responses were determined. Optical, electron back scattered diffraction (EBSD) and secondary electron imaging were used to analyse the microstructure.

\section{Results and discussion}

Figure 1 represents microstructure across the border line between the nugget and base metal. This figure captures the abrupt change in the microstructure from elongated grains to ultrafine equiaxed grains. In order to evaluate the extent of the refined nugget, detailed microhardness measurement was made with a pitch of $0.3 \mathrm{~mm}$ between each reading. Figure 2 represents microhardness distribution of the two FSP conditions investigated. The combination of $430 \mathrm{rpm}-90 \mathrm{~mm} / \mathrm{min}$, exhibited higher hardness values across the whole nugget. The width of the nugget inferred from figure 2 is close to $3 \mathrm{~mm}$ (close to the pin diameter), and this is the reason behind selecting a gauge length of $2.5 \mathrm{~mm}$ for the tensile specimen. Figures 3(a) and (b) represent colour coded orientation maps for the 430-90 and 850-90 FSP conditions, respectively. Figure 3 (c) represent statistical information on the cell size distribution for the two FSP conditions. Figures 3(e) and (d) represent the histogram for the variation of misorientation angle, for the 430-90 and 850-90 FSP conditions, respectively. This microstructural analysis is obtained by orientation imaging microscopy in the nugget zone, for a $2^{\circ}$ grain tolerance angle. The microstructure is characterized by ultrafine equiaxed grains that evolved in the nugget by dynamic recrystallization (DRX). For 430-90, the average cell size is about $0.95 \mu \mathrm{m}$, and $60 \%$ of the scanned microstructure has cell size $<1 \mu \mathrm{m}$. The average misorientation angle is about $30^{\circ}$, and the histogram shows that $72 \%$ of the boundaries are high angle boundaries $\left(\geq 15^{\circ}\right)$. For $850-90$ (higher deformation rate), the average cell size is about $2.6 \mu \mathrm{m}$, and only $7 \%$ of the scanned microstructure has cell size of $<1 \mu \mathrm{m}$. The average misorientation angle is about $17^{\circ}$, and the histogram shows that $38 \%$ of the boundaries are high angle boundaries. The EBSD scans confirm the superiority of the refined structure (smaller cell size, higher angle grain boundaries) in the 430-90 condition over the 850-90 condition, which correlates well with the high hardness profile obtained for the 430-90 condition.

Figures $4 \mathrm{a}-\mathrm{c}$ represent the true stress-true strain response, obtained from the tensile tests conducted at $250^{\circ} \mathrm{C}$, at three different strain rates, for the conditions of FSP 430-90, FSP 850-90 and as received, respectively. The true stress-true strain response can be divided into three regions. Region $I$ is the strain hardening region where the stress increases with strain until it reaches an almost constant value. Region II represents the steadystate stress at the applied strain rate. In region III, void

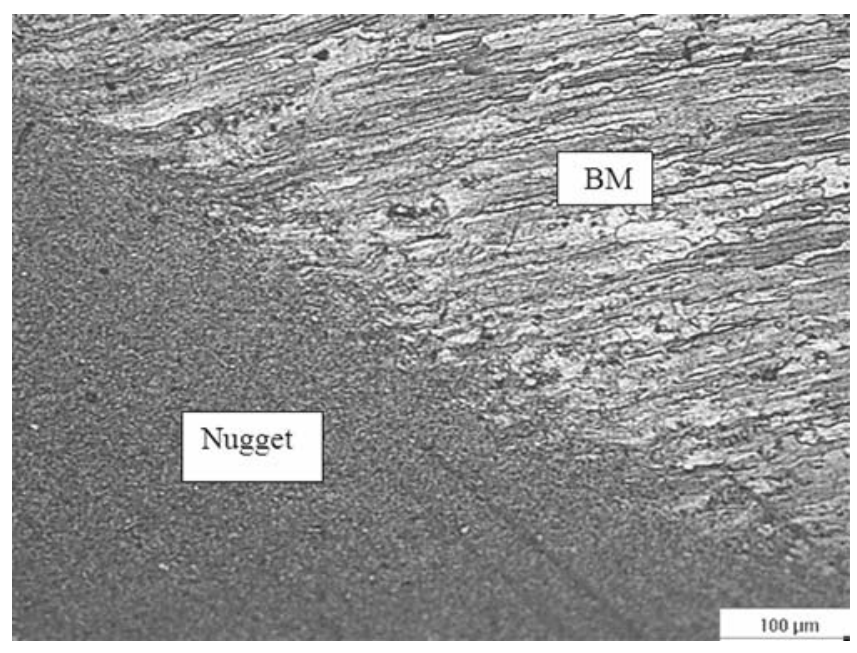

Figure 1. Microstructure across boundary line between base metal and nugget zone.

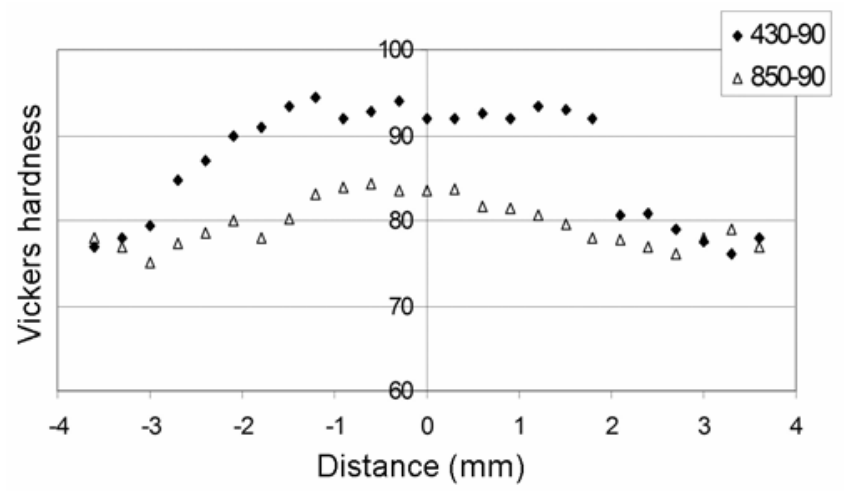

Figure 2. Microhardness distribution on transverse section for two FSP conditions. 


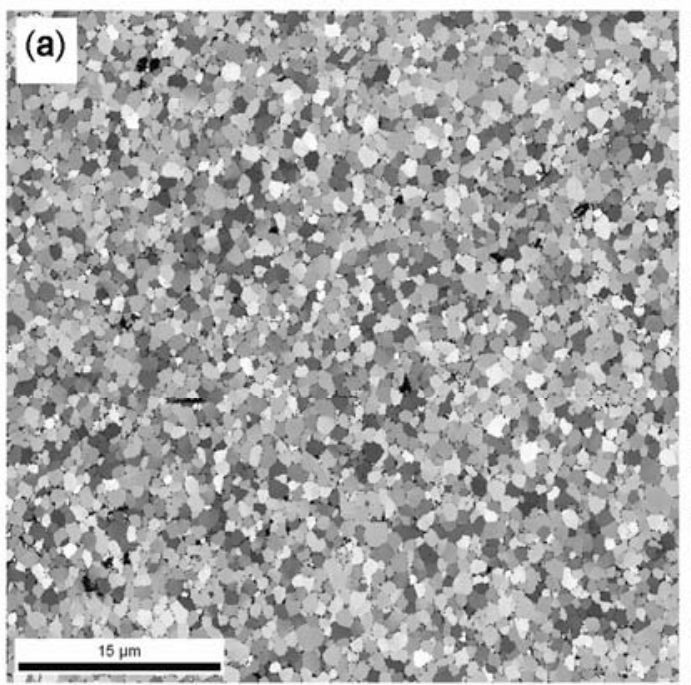

(c)

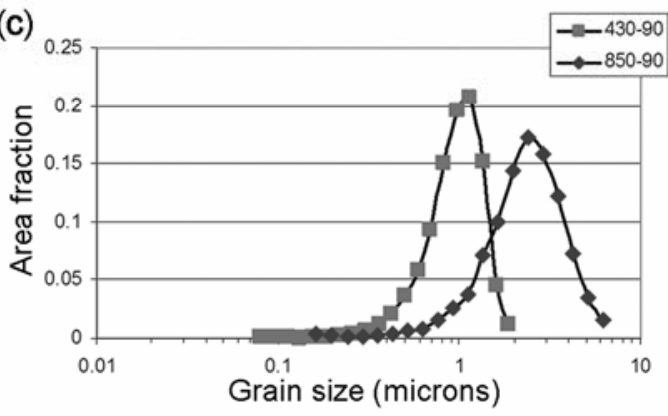

(e)

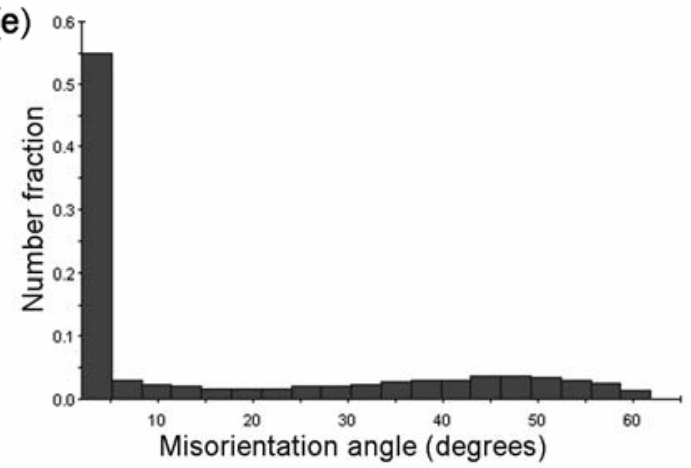

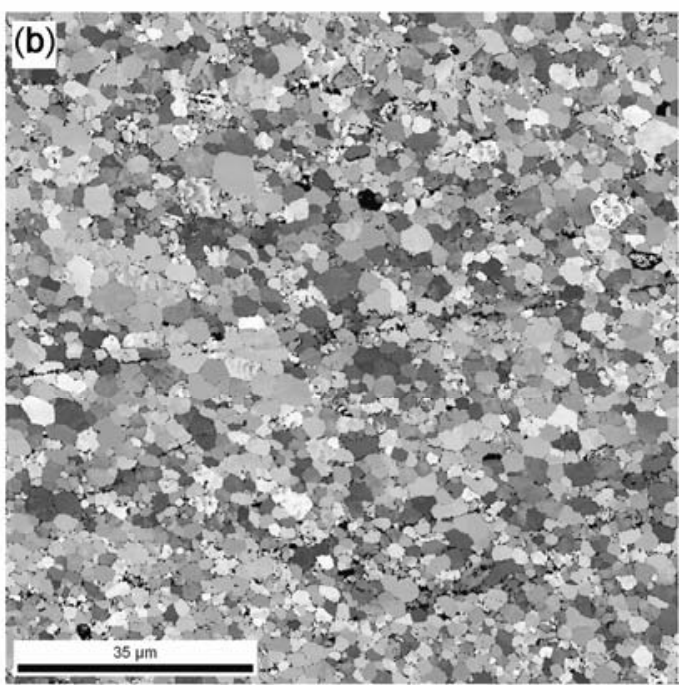

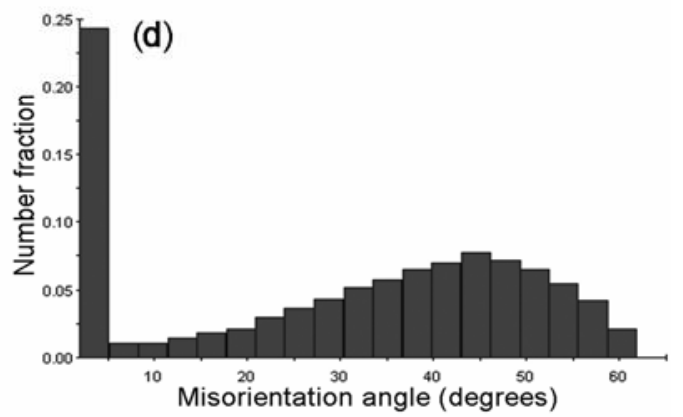

Figure 3. Colour-coded orientation maps in (a) and (b) for 430-90 and 850-90 FSP conditions, respectively. (c) represents distribution of cell size. (d) and (e) represent histogram for the variation of misorientation angle, for 430-90 and 850-90 FSP conditions, respectively.

coalescence and/or cracking evolved leading to a decrease in the flow stress and thereafter fracture. These experiments which are conducted at constant initial strain rate were used to determine ductility (elongation percent at fracture). Figure 5 represents the true stress-true strain response for the three conditions at an initial strain rate of $1 \times 10^{-4} \mathrm{~s}^{-1}$. It is clear that modifying the rolled structure to an equiaxed refined structure of 2.6 and $0.95 \mu \mathrm{m}$ has resulted in lower forming loads and pronounced increase in ductility.

Figure 6 represents the elongation to failure as a function of strain rate for the three tested conditions. It is observed that the elongation percent values increases as the strain rate decreases for the range of strain rates tested. The superiority of the elongation values for the 430-90 FSP condition over that of the other FSP condition (850-90) as well as much superior to the as received condition is also observed. These data correlates well with the superiority of the refined structure for the 43090 FSP condition, where the grains in the nugget are dynamically recrystallized to an average size of about $0.95 \mu \mathrm{m}$ with high angle of misorientation. For the 43090 condition, the increase in ductility compared to the as received condition is by a factor of $2 \cdot 3-3 \cdot 4$, whereas for 
the other FSP condition the increase is in the range of $1 \cdot 8-2 \cdot 5$. Figure 7 shows a photograph of the miniature tensile specimen used in the current study as well as the tested specimen that gave the highest elongation value (430-90) at a strain rate of $1 \times 10^{-4} \mathrm{~s}^{-1}$. It shows that the neck region has not been thinned to a point, which suggests that the failure of this material might be due to cavity formation. Figure 8 represents the secondary electron image microstructure of the fractured surface for this particular specimen, showing the presence of cavities which could be the reason for limited elongation. Figure 9 is an optical micrograph for the same sample on the gauge surface near to the fractured area. It demonstrates that the grains have maintained its refined equiaxed microstructure after deformation, indicating that grain boundary sliding plays a major role in the deformation processes. It also shows the existence of cavity streaks aligned along

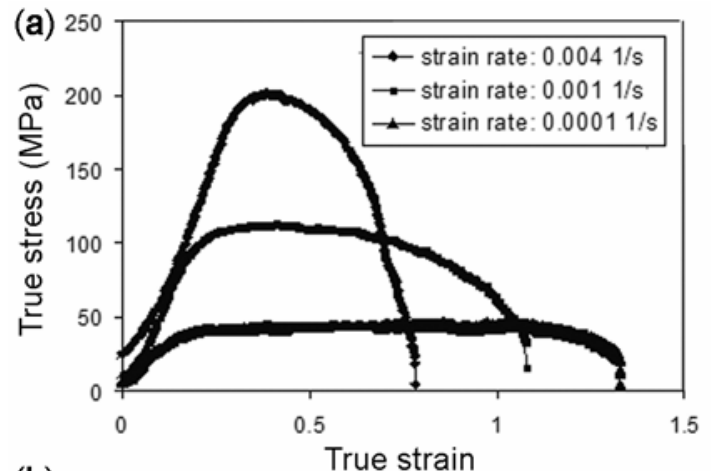

(b)

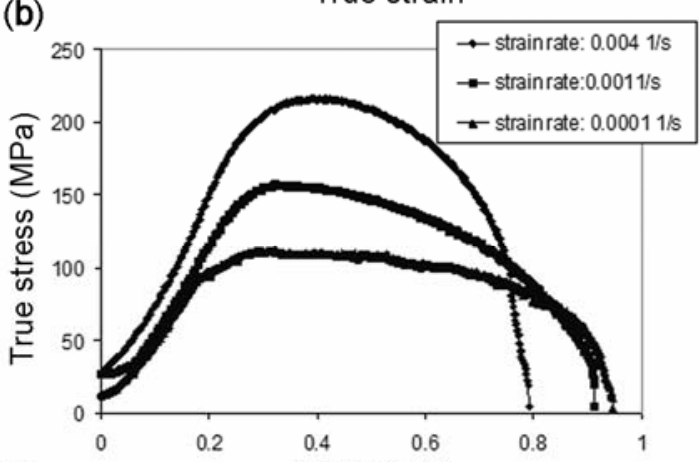

(c)

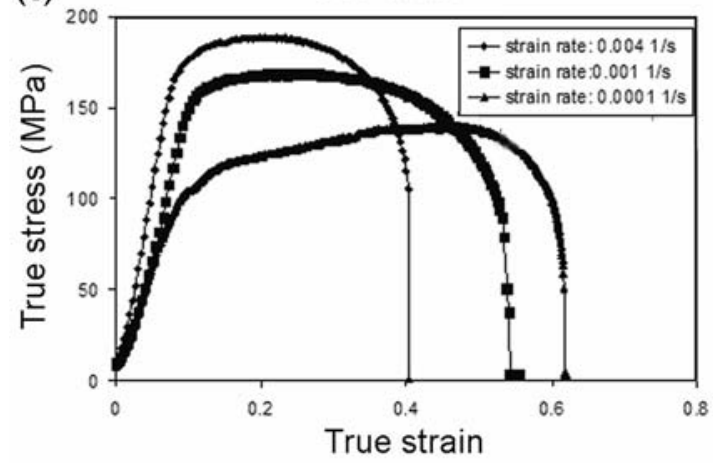

Figure 4. True stress-true strain response at $250^{\circ} \mathrm{C}$ for 430 90 in (a), 850-90 in (b) and as received in (c).

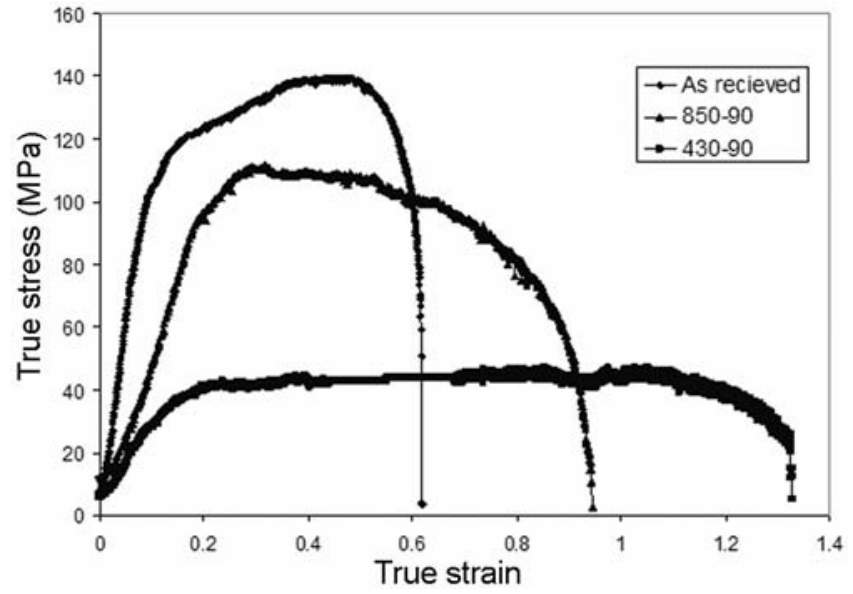

Figure 5. True stress-true strain response for three tested conditions at $250^{\circ} \mathrm{C}$, at a constant strain rate of $1 \times 10^{-4} \mathrm{~s}^{-1}$.

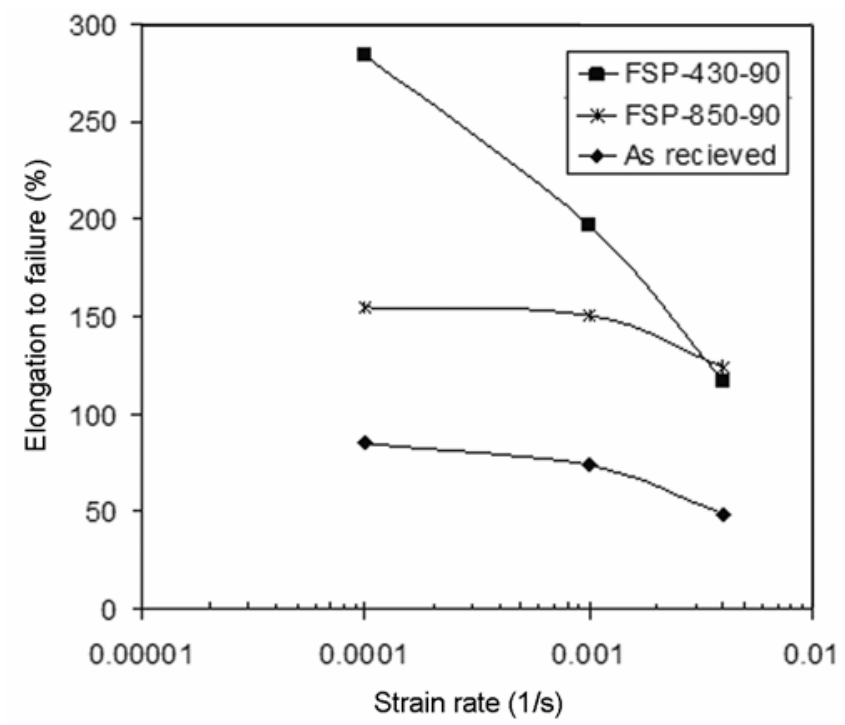

Figure 6. Elongation to failure values as a function of strain rate for all tested conditions.

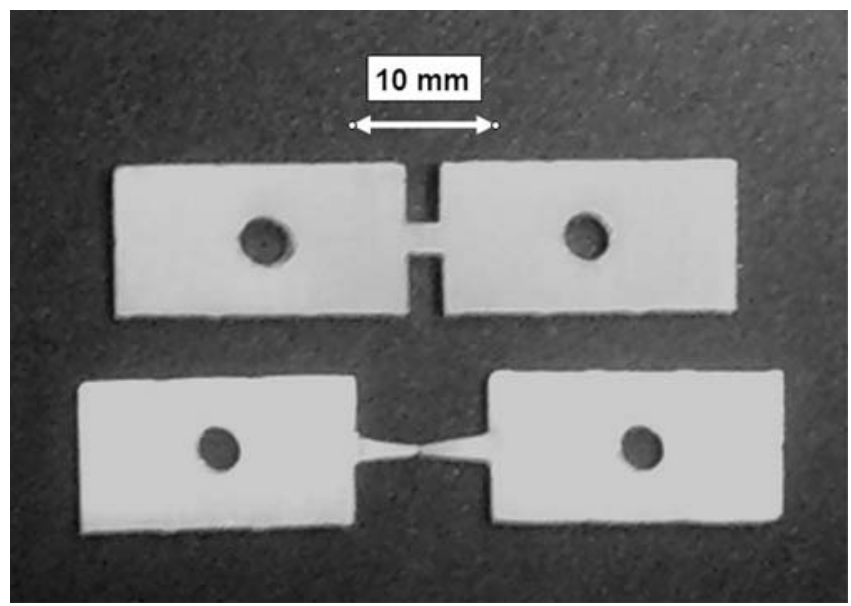

Figure 7. Photograph of miniature tensile specimen used, together with specimen that gave highest ductility (430-90 FSP condition at $1 \times 10^{-4} \mathrm{~s}^{-1}$ ). 
the tensile axis. In addition, figure 10 is a secondary electron image showing the surface topography of that same sample where it shows cavities and shiny boundaries along which the grain boundary sliding activity was taking place.

Figure 11 represents a double logarithmic plot of the flow stress $\sigma$ dependence on strain rate $\dot{\varepsilon}$ for the three tested conditions. Under steady state condition, the relation between $\dot{\varepsilon}$ and $\sigma$ at constant temperature is governed by the power law equation:

$$
\dot{\varepsilon}=A \sigma^{n},
$$

where $A$ is a constant and $n$ the stress exponent ( $n$ is equal to the reciprocal of the strain rate sensitivity parameter, $m=\partial \ln (\sigma)=\partial \ln (\dot{\varepsilon}))$. The value of $m$, for the 430

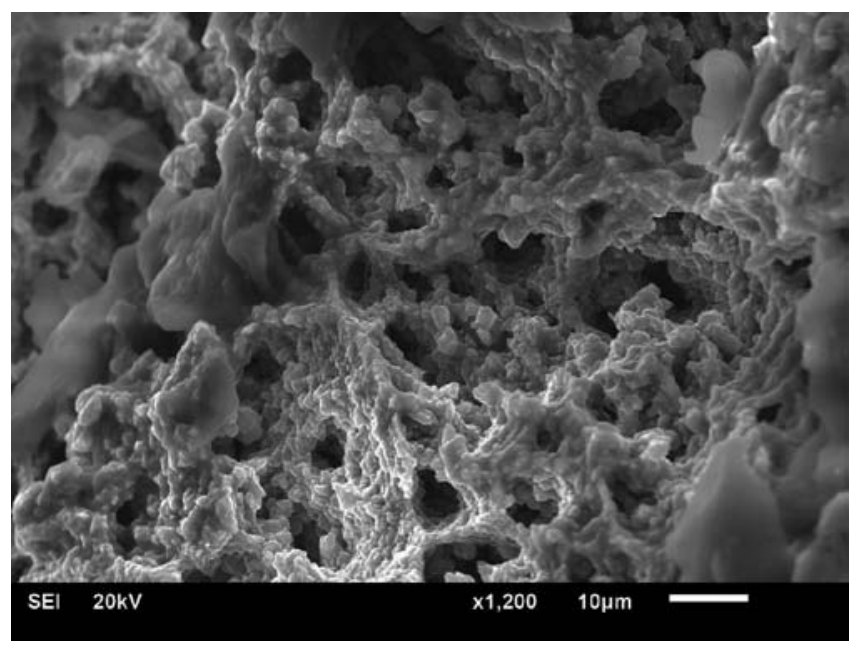

Figure 8. Secondary electron image of fractured surface for sample that gave highest ductility, exhibiting cavity formation.

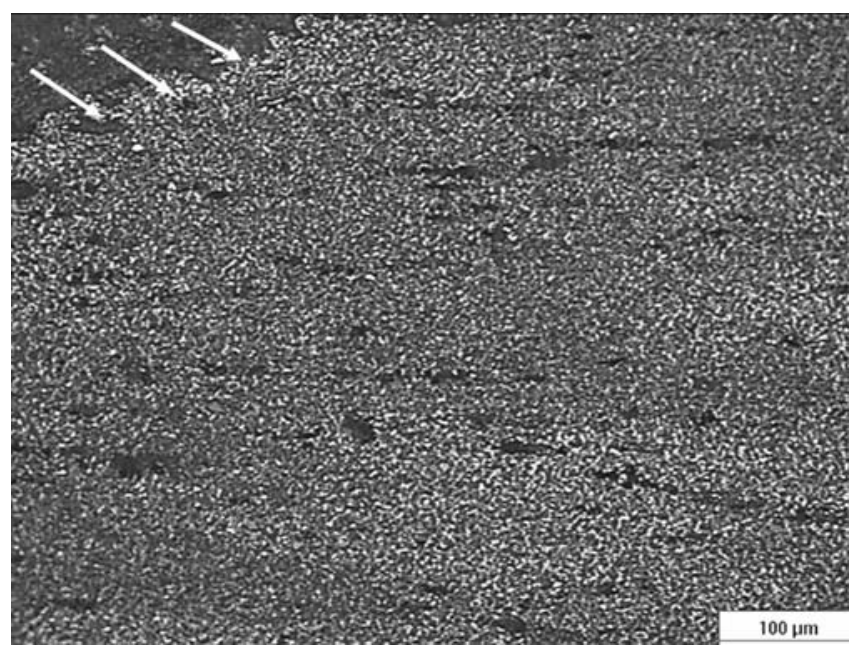

Figure 9. Microstructure of gauge surface, obtained by optical microscopy, for sample that gave highest ductility. The arrows point at fractured surface of tensile specimen.
90 FSP condition, is $0 \cdot 45$, which is higher than that for the 850-90 FSP condition $(m=0 \cdot 18)$, and still much higher than the as received condition $(m=0 \cdot 08)$. The value of $m$ of 0.45 is very close to that observed during superplastic deformation, suggesting that AA5083 can be made superplastic at low temperature $\left(250^{\circ} \mathrm{C}\right)$ if the grain size is reduced to around $1 \mu \mathrm{m}$. The microstructural features of small grain size and high angle of misorientation, promote grain boundary sliding that leads to high value of strain rate sensitivity, $m$. Dislocation climb $(n \sim 5)$ and power-law break down $(n \sim 12)$ could be rate controlling at the other two tested conditions, having a grain size of $2.6 \mu \mathrm{m}$ and elongated rolled microstructure, respectively.

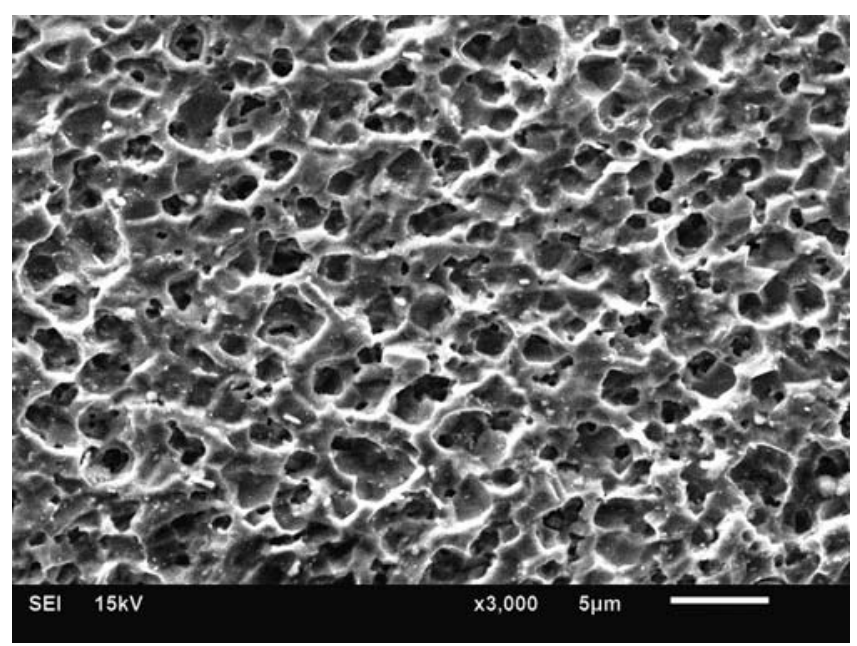

Figure 10. Secondary electron image of gauge surface for sample that gave highest ductility for 430-90 FSP condition.

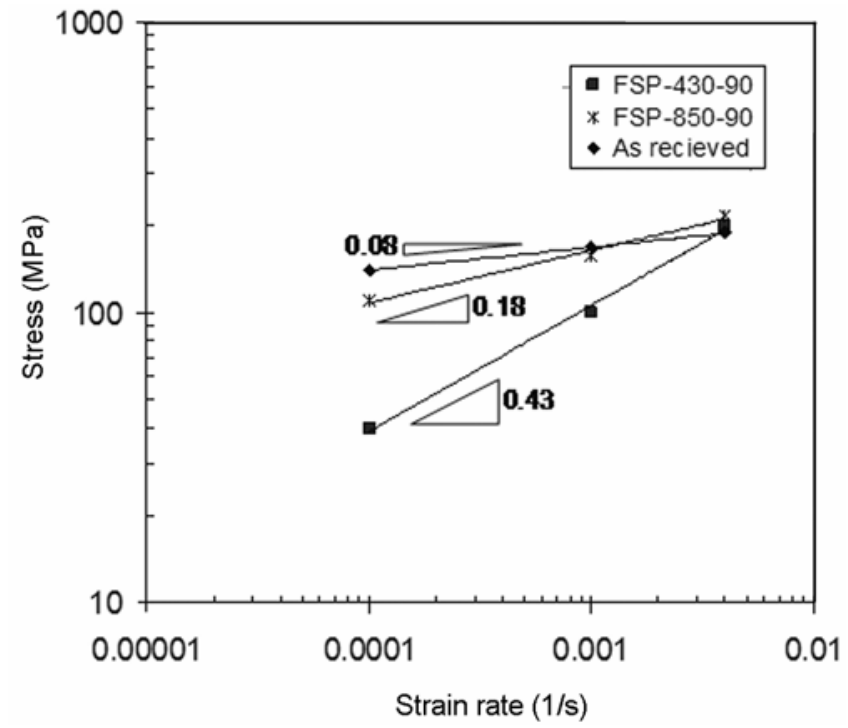

Figure 11. Double logarithmic plot for stress dependence on strain rate for three tested conditions. 
It can be shown that at constant strain rate, the true activation energy can be determined from the following equation (El-Danaf et al 2008):

$$
Q_{\mathrm{t}}=R\left[\frac{\partial \ln \left[\sigma^{n} / G^{(n-1)} T\right]}{\partial(1 / T)}\right]_{\dot{\varepsilon}}
$$

For that reason the two FSP conditions were tensile tested at 523,573 and $623 \mathrm{~K}$ at the same strain rate of $4 \times 10^{-3} \mathrm{~s}^{-1}$. Figure 12 represents a semi logarithmic plot of $\left[\sigma^{n} / \mathrm{G}^{(n-1)} T\right]$ against the reciprocal of absolute temperature for the two FSP conditions at a strain rate of $4 \times 10^{-3} \mathrm{~s}^{-1}$, to calculate the true activation energy for the rate controlling process, the value of $n$ was taken as 2 and 5 for 430-90 and 850 90 FSP conditions, respectively. The true activation energy for the 430-90 $(n \sim 2)$ condition, with a grain size of $0.95 \mu \mathrm{m}$, was calculated to be $63 \mathrm{~kJ} \mathrm{~mol}^{-1}$. The value of activation energy for grain boundary sliding is typically of the order of 0.6 of the value for lattice diffusion. Since the value of lattice diffusion of magnesium in aluminum is in the range of $115-130 \mathrm{~kJ}^{-1}$ mole $^{-1}$ (Brandes and Brook 1992) which yields $Q_{\mathrm{gb}}$ of $69-78 \mathrm{~kJ} \mathrm{~mol}^{-1}$. The experimental calculated value is close to $Q_{\mathrm{gb}}$ of magnesium in the alloy, which gives support to the calculated strain rate sensitivity value of $0 \cdot 45$. On the other hand, the true activation energy calculated for the other FSP condition $(n \sim 5)$, with a grain size of $2.6 \mu \mathrm{m}$, is $157 \mathrm{~kJ} \mathrm{~mol}^{-1}$, which is comparable to the activation energy of aluminum lattice diffusion of $143 \mathrm{~kJ} \mathrm{~mol}^{-1}$ (Brandes and Brook 1992). This suggests that dislocation climb is the rate controlling mechanism for the deformation process under this condition. The present results along with a previous work (El-Danaf et al 2010) carried out on the same material with a grain size of $1.6 \mu \mathrm{m}$ at the same temperature of $523 \mathrm{~K}$, suggest transition in the rate controlling mechanism from grain boundary sliding $(m=0.45)$ to solute drag/viscous glide $(m=0 \cdot 33)$ (El-Danaf et al 2010), to

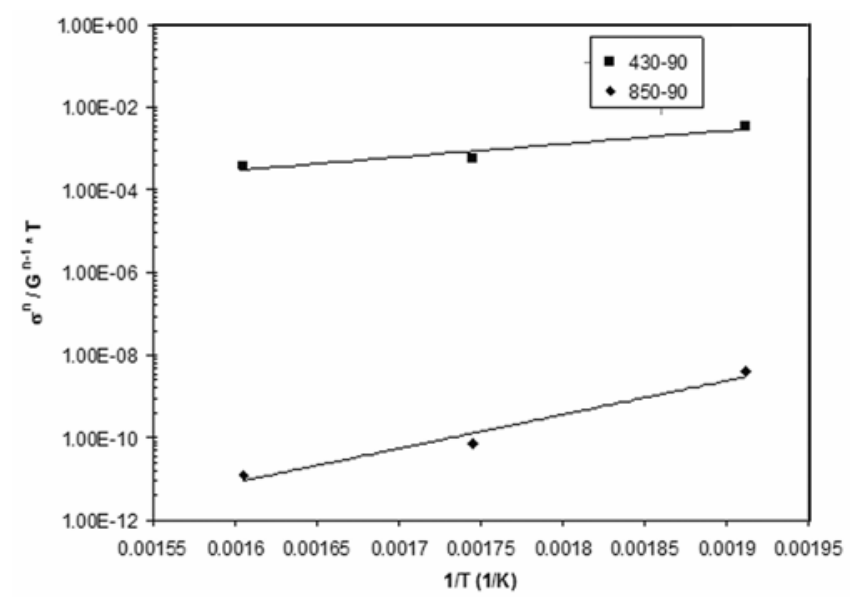

Figure 12. Semi-logarithmic plot of $\left[\sigma^{\mathrm{n}} / G^{(n-1)} T\right]$ vs reciprocal of absolute temperature. dislocation climb $(m=0.18)$ with increasing grain size from 0.95 to $1.6-2.6 \mu \mathrm{m}$, respectively.

The flow stress, $\sigma_{\mathrm{s}}$, can be expressed in a general form as a function of strain rate, $\dot{\varepsilon}$, grain size, $d$ and temperature, $T$, as follows (Oikawa 1980)

$$
\sigma_{\mathrm{s}} / G=A^{\prime}(k T / G b)^{m}(d / b)^{q}\left[\dot{\varepsilon} / D_{\mathrm{o}} \exp (-Q / R T)\right]^{m},
$$

where $A^{\prime}$ is a constant, $G$ the shear modulus, $k$ the Boltzmann's constant, $b$ the Burgers vector, $D_{\mathrm{o}}$ the frequency factor and $Q$ the activation energy for the rate controlling process. Assuming that grain boundary sliding leading to superplastic deformation is controlled by the lattice diffusion, the normalized flow stress is calculated using (1). Taking typical values of the parameters (Brandes and Brook 1992): $A^{\prime}=3.54 \times 10^{-4}, \quad m=0.5, \quad q=1, \quad D_{\mathrm{o}}=$ $10^{-4} \mathrm{~m}^{2} / \mathrm{s}, Q=20 R T_{\mathrm{m}}, G=\left(3.022 \times 10^{4}-16 T\right) \mathrm{MPa}, \sigma_{\mathrm{s}} / G$ is calculated at $\dot{\varepsilon}=1 \times 10^{-4} \mathrm{~s}^{-1}$ and $d=0.95 \mu \mathrm{m}$, to have a value of $2.23 \times 10^{-3}$ which is comparable to the experimental value of $1.83 \times 10^{-3}$. This discrepancy between the calculated value of $\sigma_{\mathrm{s}} / G$ and the experimental one may arise from neglecting the contribution of grain boundary diffusion under superplastic condition, at the present experimental conditions. For grain size of $2.6 \mu \mathrm{m}$, and strain rate $\dot{\varepsilon}=1 \times 10^{-4} \mathrm{~s}^{-1}$, dislocation climb is rate controlling. Thus taking the typical values of $A^{\prime}=3.5 \times$ $10^{-2}, m=0 \cdot 2, q=0$ (Brandes and Brook 1992), with $D_{\mathrm{o}}$, $Q$ and $G$ having the same values as above, the calculated $\sigma_{\mathrm{s}} / G$ has a value of $2.86 \times 10^{-3}$ as compared to the experimental value of $4.6 \times 10^{-3}$. This difference may arise from not considering the effect of dislocation core diffusion under dislocation climb control at a relatively low temperature of $523 \mathrm{~K}$. In a recent study (Hsiao and Huang 2002) reported that the low-temperature superplastic deformation in thermomechanically-treated, fine grained AA 5083 was controlled by a combination of dislocation power law, dislocation core diffusion and grain boundary sliding mechanisms.

\section{Conclusions}

(I) Dynamically recrystallized refined microstructure obtained in the condition of 439-90 FSP exhibited much superior properties (smaller cell size and higher angle grain boundaries) over that of 850-90 FSP condition.

(II) Tensile elongations of friction stir processed AA5083 (430-90) has increased by a factor of 2.3-3.4 compared to the as-received rolled material at $250^{\circ} \mathrm{C}$. The strain rate sensitivity inferred is 0.45 which is close to that observed in superplastic region $(m=0 \cdot 5)$.

(III) Lower forming loads are experienced in the 430-90 FSP condition which is an indication that grain-boundary sliding plays a major role in the deformation process.

(IV) Cavity formation during grain boundary sliding, in commercial alloys, limits the amount of achievable ductility. 


\section{Acknowledgement}

This project was supported by King Saud University, Deanship of Scientific Research, College of Engineering, Research Centre.

\section{References}

Abo-Elhkier M and Soliman M S 2006 J. Mater. Eng. Perform. 1576

Azushima A et al 2008 CIRP Annals-Manufac. Technol. 57716

Brandes E A and Brook G B (eds) 1992 Smithells metals reference book (Oxford: Butterworth-Heinemann) 7th edn

Cavalierea P and Squillace A 2005 Mater. Charact. 55136

Chaudhury P K and Mohamed F A 1988 Acta Matell. 361099

Duong K and Mohamed F A 2000 Philos. Mag. A80 2721

Eizadjou M, Manesh H D and Janghorban K 2009 J. Alloys \& Compd. $\mathbf{4 7 4} 406$
El-Danaf E A, Almajid A A and Soliman M S 2008 J. Mater. Eng. Perform. 17572

El-Danaf E A, El-Rayes M M and Soliman M S 2010 Mater. Des. 311231

Hsiao I C and Huang J C 2002 Met. Trans. A33 1373

Johannes L B, Charit I, Mishra R S and Ravi Verma 2007 Mater. Sci. Eng. A464 351

Ma Z Y, Mishra R S and Mahoney M W 2002 Acta Mater. 50 4419

Mishra R S and Mahoney M W 2004 Metal superplasticity enhancement and forming process, US Patent 6,712,916

Mohamed F A 1988 J. Mater. Sci. 7215

Mohamed F A 2002 Met. Trans. A33 261

Oikawa H 1980 Mater. Sci. Eng. A44 211

Park K T, Hwang D Y, Lee Y K, Kim Y K and Shin D H 2003 Mater. Sci. Eng. A341 273

Soliman M S 1994 Scr. Met. Mater. 31439

Soliman M S 1995 Scr. Met. Mater. 31919

Yousefiani A and Mohamed F A 1998 Met. Trans. A29 1653 